\title{
A versatile microcomputer-based multiple-field tachistoscope
}

\author{
THOMAS BIDDLE PERERA \\ Montclair State College, Upper Montclair, New Jersey 07043
}

\begin{abstract}
A newly introduced microcomputer in its most basic form provides a wide variety of stimulus display capabilities at an extremely low price. Several simple illustrative programs demonstrate its ability to present any number of visual stimuli in sequence and record response latencies, thus duplicating the functions of a multiple-field tachistoscope and associated responserecording instrumentation.
\end{abstract}

The most widely available inexpensive microcomputer system, the Radio Shack TRS-80, has proved to be a reliable and useful unit for general statistical use in the laboratory. It consists of a standard typewriter keyboard with the microcomputer and memory in its base, a video monitor, and a standard cassette tape recorder for storage and retrieval of programs or data. The graphics capabilities of this and other packaged computers also lend themselves to uses as visual displays for experiments in perception and cognition. Using the basic computer system at a price well under $\$ 1,000$, it is possible to fully instrument experiments which, in the past, required a very expensive multiplefield tachistoscope, external response keys, external reaction timers, and power supplies or minicomputer systems costing over $\$ 8,000$. For researchers who are unfamiliar with microcomputers, a well-organized instruction manual teaches the basic concepts of the TRS-80 in approximately $2 \mathrm{~h}$.

Illustrative programs are presented to show how a microcomputer can be used to instrument typical psychological experiments. The programs may easily be modified to fit specific experimental requirements.

\section{SOFTWARE FOR USING THE TRS-80 AS A TACHISTOSCOPE}

The two types of BASIC language statements that make visual stimulus displays possible are the SET $(X, Y)$ and the PRINT AT X, "text" statements. The SET $(X, Y)$ statement allows the user to set, or turn on, a square of light $.1 \mathrm{~cm}$ wide and $.3 \mathrm{~cm}$ high at any chosen $\mathrm{X}$ and $\mathrm{Y}$ coordinates on the darkened $20.0 \mathrm{~cm}$ wide $\mathrm{x} 17.0 \mathrm{~cm}$ high screen of the video monitor. The luminance may be adjusted from $2.7 \log \mathrm{fL}$ to zero, and the contrast may be adjusted by varying the background brightness. Geometric linearity of the display can be adjusted to better than $10 \%$ across the screen and brightness stability is better than $5 \%$. The monitor screen is divided into 128 units $(0$ to 127) on the horizontal, or $X$, axis and 48 units ( 0 to 47$)$ on the vertical, or $Y$, axis.
The following programs illustrate the use of the SET $(X, Y)$ statement to present a fixation point in the middle of the screen and to alternate two points to produce the "phi phenomenon." The fixation point is produced by the simple statement Set $(64,24)$. This turns on a small block of light in the center of the screen. It may be turned off by the statement RESET $(64,24)$ or by the command CLS, which is used to completely clear the screen.

The phi phenomenon can be produced by the following program, which turns on a block of light on the left side of the screen, waits for $200(2.4 \mathrm{msec})$ counts, turns off the left block of light, turns on the right block of light, waits, and then repeats itself.

10 CLS
20 SET $(44,24)$
30 FOR T $=1$ TO 200
40 NEXT T
$50 \operatorname{RESET~}(44,24)$
60 SET $(84,24)$
70 FOR T $=1$ TO 200
80 NEXT T
90 RESET $(84,24)$
100 GOTO 20

This program may easily be modified to produce any desired stimulus configuration and interstimulus delays. The distance between the subject and the display may be varied to produce any desired stimulus size (visual angle). The formula for calculating the visual angle subtended by a stimulus is: visual angle (in degrees) $=57.3 \times$ stimulus size (in millimeters) $\div$ distance from subject's eyes to stimulus (in millimeters). This formula is accurate within $1 \%$ up to 10 deg of visual angle.

To produce a tachistoscope, the PRINT AT X statement is used. It permits $.3 \times .6 \mathrm{~cm}$ letters, complete words, or complex text to be displayed starting at any screen position indicated by $\mathrm{X}$. Text programming is facilitated by a printed grid of 64 columns by 16 rows showing the screen's positions, numbered 
0 to 1,023 . Thus, the statement PRINT AT 0 , "RED" would illuminate the word "RED" in the upper left corner of the screen.

The following tachistoscope program presents a fixation point for $5002.4-\mathrm{msec}$ counts, presents a word to the left of the fixation point, waits, presents a word to the right of the fixation point, waits for the subject to press a response key, and stores the latency until instructed to display it in the upper left corner of the display screen in an area blocked off from the subject's vision. The basic 4,000-word memory of the computer is more than adequate to accept elaborate multiple-stimulus variations of this program and will accommodate even the most elaborate tachistoscopic presentations without overload.

\section{CLS}

$20 \operatorname{SET}(64,24)$

30 FOR T $=1$ TO 500

40 NEXT T

50 CLS

60 PRINT AT 531, "GREEN"

70 FOR A=1 TO 100

80 NEXT A

90 CLS

100 PRINT AT 556, "BROWN"

110 FOR B=1 TO 30

120 NEXT B

$130 \mathrm{CLS}$

140 FOR $C=1$ TO 10000

\section{NEXT C}

200 PRINT AT 0,C

This program turns on a fixation point as soon as RUN followed by ENTER (RETURN on most computers) is typed. The fixation point stays on for 500 2.4-msec counts and then the screen is cleared. The word "GREEN" is presented to the left of the fixation point at Location 531 for $1002.4-\mathrm{msec}$ counts, the screen is cleared, the word "BROWN" is presented to the right of the fixation point at Location 556 for 30 2.4-msec counts, and the screen is again cleared. At this point, the computer starts counting values of C from 1 to 10,000 . The subject responds by pressing the BREAK key, which halts the program but retains the last value of $C$. To retrieve this latency, the experimenter types "RUN 200" followed by the ENTER key. The computer prints the value of $\mathrm{C}$ in the upper left corner of the screen, out of sight of the subject.

Simple modifications of these programs allow different stimuli to be presented, different exposure times, and different interstimulus intervals. The timing counts are approximately $2.4 \mathrm{msec}$ but should be checked on each individual computer to assure accuracy of stimulus presentation times and response measurements.
(Received for publication April 10, 1978; revision accepted June 15,1978 .) 